\title{
Application of MIR Spectroscopy to the Evaluation of Chemical Composition and Quality Parameters of Foal Meat: A Preliminary Study
}

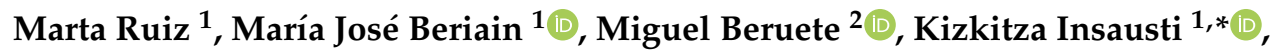 \\ José Manuel Lorenzo $^{3}$ D and María Victoria Sarriés $1, *(\mathbb{D})$ \\ 1 Research Institute for Innovation and Sustainable Development in Food Chain (IS-FOOD), Universidad \\ Pública de Navarra, Campus de Arrosadía, 31006 Pamplona, Spain; marta.ruiz@unavarra.es (M.R.); \\ mjberiain@unavarra.es (M.J.B.) \\ 2 Multispectral Biosensing Group, Navarrabiomed, Complejo Hospitalario de Navarra (CHN), Instituto de \\ Investigación Sanitaria de Navarra (IdiSNA), Universidad Pública de Navarra (UPNA), Irunlarrea 3, \\ 31008 Pamplona, Navarra, Spain; miguel.beruete@unavarra.es \\ 3 Centro Tecnológico de la Carne de Galicia (CTC), Rúa Galicia 4, Parque Tecnológico de Galicia, San Cibrao \\ das Viñas, 32900 Ourense, Spain; jmlorenzo@ceteca.net \\ * Correspondence: kizkitza.insausti@unavarra.es (K.I.); vsarries@unavarra.es (M.V.S.)
}

Received: 30 March 2020; Accepted: 30 April 2020; Published: 5 May 2020

\begin{abstract}
The aim of this work was to study the potential of mid-infrared spectroscopy to evaluate the chemical composition and quality parameters of foal meat according to differences based on slaughter ages and finishing diets. In addition, the wavelength ranges which contribute to this meat quality differentiation were also determined. Important characteristics as moisture and total lipid content were well predicted using Mid-Infrared Spectroscopy (MIR)with $\mathrm{Rv}^{2}$ values of $82 \%$ and $66 \%$, respectively. Regarding fatty acids, the best models were obtained for arachidonic, vaccenic, docosapentaenoic acid (DPA), and docosahexaenoic acid (DHA) with $\mathrm{Rv}^{2}$ values over $65 \%$. Quality parameters, as instrumental colour and texture and sensory attributes did not reach high prediction coefficients $\left(R^{2}\right)$. With the spectra data of the region $2198-1118 \mathrm{~cm}^{-1}$, samples were accurately classified according to slaughter age $(78 \%)$ and finishing diet $(72 \%)$. This preliminary research shows the potential of MIR spectroscopy as an alternative tool to traditional meat chemical composition methods. Finally, the wavelength range of the spectrum from 2198 to $1118 \mathrm{~cm}^{-1}$ showed good results for classification purposes.
\end{abstract}

Keywords: MIR spectroscopy; foal meat; chemical composition; quality parameters

\section{Introduction}

Nowadays, high assurance of quality and safety during food production is being extremely demanded. Thus, strict controls both throughout the production and during the marketing process are required [1]. This demand and the agricultural industries supervision make highly desirable, food analysis methods which are speed, ease to use, with non-preparation or minimum sample preparation, with non-destruction of samples, low cost, and environmentally sustainable [2,3]. In this way, the Near-Infrared Spectroscopy (NIR) and Attenuated Total Reflectance-Fourier Transform Mid-Infrared Spectroscopy (ATR-FT/MIR) are practical options, as they fulfil the requirements aforementioned. MIR spectroscopy applications in food analysis are diverse although its current use is limited. Especially for meat, several topics have been studied: (1) determination of chemical composition, (2) detection of microbiological spoilage, (3) authentication of products or (4) detection of meat adulterations [1]. Nevertheless, there is a lack of knowledge regarding the use of MIR spectroscopy to evaluate meat 
quality, concerning not only chemical composition, but also texture, colour parameters, or even sensory attributes. Regarding this last group, Yancey et al. [4] were able to predict the tenderness and overall appraisal evaluated by a consumer panel by the employment of non-invasive techniques such as NIR spectroscopy. In addition, Ripoll et al. [5], obtained successful results predicting some chemical parameters (moisture, fat, water holding capacity), the shear force and sensory tenderness by NIR spectroscopy.

According to world consumption of foal meat, Mongolia (5.81 kg) is the country with the highest horsemeat supply per capita followed by Kazakhstan $(4.92 \mathrm{~kg})$, Kyrgyzstan $(3.50 \mathrm{~kg})$, Iceland $(2.19 \mathrm{~kg})$, Switzerland $(0.73 \mathrm{~kg})$ and Italy $(0.70 \mathrm{~kg})$ [6]. Currently, studies on foal meat have noticeably arisen because of its healthy properties and sustainable production, which make it an alternative meat for consumers, whose demand for healthy and safe products is continuously increasing [7]. Nevertheless, this kind of meat must be more exhaustively defined according to different factors as slaughter age or feeding, which play an important role in meat quality [8,9]. In this way, rapid, non-destructive techniques such as MIR spectroscopy would be helpful to differentiate foal meat regarding the mentioned factors. Besides, NIR spectroscopy has been widely applied in the food industry, but new wavelengths of the spectrum should be studied in order to try and overcome the current limitations that the near-infrared spectrum has.

Thus, the general objective of the present work was to investigate the potential of MIR spectroscopy to evaluate the chemical composition and quality parameters of foal meat from animals of different ages and feeding regimes. In addition, the wavelength ranges which contribute to this meat quality differentiation were also determined.

\section{Materials and Methods}

\subsection{Animal Management and Meat Sampling}

Forty-six foals obtained by crossing Galician Mountain mares with a Burguete stallion were used. The animals were reared under semi-extensive conditions. A fuller description of the animal management has been published in Ruiz et al. [10]. Twenty-two foals were slaughtered at 13 months $(13 \mathrm{M})$ and another 24 at 26 months of age (26M). Prior to slaughter, all the foals were supplemented for a fattening period of about 104 days. Two study groups were formed by randomly assigning 11 foals from the $13 \mathrm{M}$ group and 12 foals from the $26 \mathrm{M}$ group to be supplemented on pasture with a standard concentrate (SC) (2 kg per foal and day) and pasture; and 11 foals from the 13M group and 12 foals from the $26 \mathrm{M}$ group to be supplemented on pasture with a linseed-enriched concentrate (5\%) (LC) ( $2 \mathrm{~kg}$ per foal and day) and pasture.

Foals were slaughtered and dressed according to the specifications outlined in the European legislation (Council Regulation 1099/2009).

Immediately after slaughter, hot carcass weight was determined, and once chilled for $24 \mathrm{~h}$ at $4 \pm 1{ }^{\circ} \mathrm{C}$, cold carcass weight $(\mathrm{kg})$ and dressing percentage $(\%)$ were determined 10]. At this point, the left half-carcasses were transported under refrigeration to the research center pilot plant at $4 \pm 1{ }^{\circ} \mathrm{C}$. Longissimus thoracis (LDT) muscle was removed from the left half-carcasses. This muscle was employed because it is the reference muscle in meat science studies, and it is one of the most commercially valuable muscles with respect to foal meat. Twenty-four hours after removal, $46 \mathrm{LDT}$ samples were analysed. In order to carry out the analyses, the LDT section ranging between the seventh and the twelfth rib was employed, following the same cutting order for all the analyses. They were then sliced into five $20 \mathrm{~mm}( \pm 0.2)$ thick steaks (FIRMAQ, V-900, Lorca, Spain) simulating the standard cutting thickness at the sale point. Then, they were vacuum-packaged and frozen at $-18^{\circ} \mathrm{C}( \pm 2)$ to be transported to the Public University of Navarra where samples were frozen-preserved for ninety days and then, prior to each analysis, samples were thawed overnight in a fridge at $4+1{ }^{\circ} \mathrm{C}$. 


\subsection{Meat Physicochemical Analysis}

\subsubsection{Chemical Composition}

The moisture, protein, ash, total lipids content, $\mathrm{pH}$, and water holding capacity were performed following the procedure of Dominguez et al. [11]. Total and soluble collagen content were determined from the hydroxyproline content [12].

\subsubsection{Meat Colour Evaluation}

The spectral reflectance of the samples, provided by a Minolta CM2002 spectrophotometer with a D65 illuminant and a $10^{\circ}$ standard observer, was used to calculate the proportion of each pigment form. Relative myoglobin $(\mathrm{DMb})(\%)$, metmyoglobin $(\mathrm{MMb})(\%)$ and oxymyoglobin $(\mathrm{OMb})(\%)$ contents were obtained from the reflex attenuance at the isobestic points 572, 525, 473, and $700 \mathrm{~nm}$ [13]. Reflectance values were converted into absorbance values according to the formula:

$$
A=2-\log 10 R
$$

where $\mathrm{A}$ is absorbance and $\mathrm{R}$ is reflectance [14].

To assess meat colour by Image Analyses, RGB colour values were determined for each sample ( $R, G$, and $B$ ) individually. Where $R$ stands for red colour, $B$ means blue, and $G$ stands for green. The colour range varies from 0 to 225 . The value " 0 " means: $100 \%$ of the light is reflected, and value " 225 " means: $100 \%$ of the light is absorbed. Samples were examined under the microscope and both sides photographed. The microscope images obtained were digitised by the employment of an image analysis software (ImageJ 1.47, LOCI, University of Wisconsin, WI, USA). The average red, green and blue values were obtained. The CIEL* $a^{*} b^{*}$ system was also employed. Lightness ( $\left.L^{*}\right)$, redness $\left(a^{*}\right)$, yellowness $\left(b^{*}\right)$, chromaticity $\left(C^{*}\right)$ and hue $\left(h^{*}\right)[15]$ were assessed following the methodology established by Mendizabal et al. [16].

\subsubsection{Intramuscular Fatty Acids Analysis}

Fatty acid profile was determined as it is shown in Domínguez et al. [14]. But, for this study, the most remarkable fatty acids from the nutritional point of view were selected. These are: stearic $(\mathrm{C} 18: 0)$, oleic $(\mathrm{C} 18: 1 \mathrm{n} 9 \mathrm{c})$, linoleic $(\mathrm{C} 18: 2 \mathrm{n} 6 \mathrm{c})$, linolenic (C18:3n3), arachidonic (C20:4n6) and vaccenic (CLA precursor) (C18:1n11t) acids. Finally, eicosapentaenoic (EPA, C20:5n3), docosapentaenoic (DPA, C22:5n3), docosahexaenoic (DHA, C22:6n3) and n-6 total PUFA content were studied as well.

\subsubsection{Texture Analysis}

The maximum shear force was assessed using a Warner-Bratzler shear force (WBSF) (N) device. Eight replicates per sample of $1 \mathrm{~cm}^{2}$ (square cross-section), with muscle fibres parallel to the longitudinal axis of the sample were analysed. A TA-XT2i texturometer (Stable Micro Systems, Surrey, United Kingdom) was used connected to an IBM-compatible Foxen computer, with microprocessor AutenticAMD-K6 ${ }^{\mathrm{TM}}$ 3D processor. The program employed was "Texture Expert" version 1.22 to Windows (Stable Micro Systems, Surrey, UK).

\subsection{Consumer Panel Evaluation}

A consumer panel integrated by 247 panelists from Pamplona (Navarra, Spain) was employed. The demographic distribution of consumers for the experiment was as follows: according to gender ( 50.3 vs. $49.7 \%$ for male and female, respectively), age ( 36.9 vs. 35.2 vs. 19.7 vs. $8.3 \%$, for age ranges of $20-34,35-50,51-65$, and $>65$ respectively), and education (73.2 vs. 20.5 vs. $6.3 \%$, for degree, secondary, and elementary studies, respectively) and incomes (3.2 vs. 12.1 vs. 45.0 vs. $36.0 \%$, for income ranges of $<900 € /$ month, $900 €-1.500 € /$ month, $1.500 €-3.000 € /$ month, and $>3.000 € /$ month, respectively). The methodology used for consumer taste panels was previously described by Beriain et al. [17]. 
Nine sessions integrated by $27 / 28$ consumers per session took place. The frozen steaks were thawed at $2{ }^{\circ} \mathrm{C}$ for approximately $24 \mathrm{~h}$ and cooked on a grill (Magefesa, Spain) according to the AMSA guidelines [18] until they reached $70{ }^{\circ} \mathrm{C}$ of internal temperature. Four steak-pieces (one from each age and diet combination) were presented to the consumers one by one in a random order [19]. Panelists were asked to rate their liking for tenderness, juiciness, and their overall appraisal of the samples. A 9-point hedonic scale was used, being $1=$ "Dislike extremely", $2=$ "Dislike very much", $3=$ "Dislike moderately", $4=$ "Dislike slightly", $5=$ "Neither like nor dislike", $6=$ "Like slightly", $7=$ "Like moderately", $8=$ "Like very much" and $9=$ "Like extremely".

Statistical analysis was conducted using the IBM SPSS Statistics 25 for Windows (SPSS Inc. Corporation, NY, USA) to obtain the descriptive statistics of the physical, chemical, and consumer evaluation of the samples. The mean plus standard deviation and the coefficient of variation (\%) were obtained.

\subsection{Mid-Infrared Spectra Measurements and Spectral Acquisition}

All the samples were thawed overnight in a fridge at $4 \pm 1{ }^{\circ} \mathrm{C}$, prior to the analysis with the ATR-FT/MIR spectroscopy. The measuring instrument used in this research was a FTIR Vertex $80 \mathrm{v}$ spectrometer (Bruker, Ettlingen, Germany). This equipment allows to work under vacuum conditions in the optical system which reduces the possible interferences produced by the water vapor or the carbon dioxide in the measurements. This device is located in a clean room certified according to ISO 14644-1:2015. There, the concentration of particles present in the air and the temperature (constantly maintained at $22{ }^{\circ} \mathrm{C}$ ) were controlled. The measurements were made with an accessory A225 / QPlatinum-ATR (Bruker, Germany) made of a diamond crystal.

Firstly, a reference spectrum was taken with the ATR device empty, and then the spectrum of each of the samples was measured. It was necessary to place the meat sample on the crystal, ensuring the entire crystal surface was completely covered and that there was a perfect contact between the sample and the crystal. In total, 6 replicates were performed per sample. For each sample, 32 scans in the $4000-400 \mathrm{~cm}^{-1}$ spectral range were recorded with a resolution of $4 \mathrm{~cm}^{-1}$.

\subsection{Selection of Optimal Wavenumber Region and Spectral Pre-Treatment Method}

Different wavenumber ranges and pre-treatment methods (first/ second derivative, standard normal variate, maximum/ minimum or vector normalisation, multiplicative scatter correction or removal of constant slope) were studied to find models with better performance. These pre-treatments were employed on the performance of PLS as a previous step before being evaluated. The selection of pre-treatments and spectral ranges supplied by models represents a key parameter to be taken into account in a multivariate analysis according to a specific program of chemometrics, OPUS Quant 2 (Bruker, Ettlingen, Germany).

\subsection{Data processing and Calibration Models}

\subsubsection{Regression Model}

Partial least squares (PLS) regression is a supervised analysis based on the relation between spectral intensity and sample characteristics [20]. In the present study, PLS technique was used to obtain quantitative prediction of the parameters of interest and it is generally carried out in two steps. To construct a model, the first step is to collect a calibration set of samples for establishing a multiple linear regression between the Mid-Infrared Region (MIR) spectra and the various parameters of the sample set in order to perform a calibration. The second step consists in testing developed calibration models on validation sets so as to verify model accuracy and robustness. 
The chemical bonds associated with each peak of the FTIR spectra were determined by analyzing the physicochemical composition and sensory properties of the samples, by correlations among the bands with larger intensity, and by comparing the wavenumbers with the literature [3].

Then, the analysis was particularised to the physical, chemical, and sensory properties of the samples, and prediction models were built using the results obtained by the described methods as reference values. Spectral data pre-treatments such as standard normal variate (SNV), multiplicative scatter correction (MSC) and first or second order derivatives were applied to the spectra to reduce scattering effects and to correct peak overlap and baseline drifts. The models were built using a specific program of chemometrics, OPUS Quant 2 (Bruker, Ettlingen, Germany).

\subsubsection{Validation Model}

The calibration models were developed using the Partial Least Square (PLS) regression method and validated by cross-validation. The main advantage of cross-validation is that a small number of samples are required because the same set of samples is used to calibrate and validate the method. The optimum number of factors in the PLS calibration models was indicated by the lowest number that gave the minimum value of the root mean square error (RMSE) in cross-validation, in order to avoid overfitting of the models. In each variable analysed, the range of wavenumbers with more information in their absorbance and the best pre-treatment method were selected using the OPUS Quant 2 program. During the calibration and prediction stages, the outliers were detected and kept out of the prediction models. The models were tested to predict the different parameters in the independent validation set and the best calibration models were selected based on the highest determination coefficient of calibration $\left(\mathrm{Rc}^{2}\right)$, determination coefficient of cross-validation $\left(\mathrm{Rv}^{2}\right)$ and the lowest root mean square error of calibration (RMSEC), root mean square error of cross-validation (RMSECV) and the ratio of prediction to deviation (RPD). These models enable a quantitative estimation of the physicochemical composition, colour parameters, and sensory attributes of the different samples depending on the absorbance intensity.

\subsection{Multivariate Analysis}

\subsubsection{Pearson's $(r)$ coefficients of correlation}

Pearson's $(r)$ coefficients of correlation between the meat quality response variables were determined. In addition, correlations between the most relevant wavelengths found throughout the spectra were studied. A positive correlation coefficient close to 1 indicates that when band intensity increases, the signal of the other band increases as well. This means that the same link or structural unit is in different bands with different modes of vibration. A negative correlation coefficient nearby to -1 reflects that an increase in a signal coincides with the decrease in the other compared signal. In no case, correlation must be understood as synonymous with causality.

\subsubsection{Principal Component Analysis (PCA)}

With the most representative wavelength range obtained by the models, principal component analysis (PCA) was applied to reduce the number of variables. PCA determines linear combinations of the original variables to summarise the data with minimal loss of information. Varimax rotation was applied to the factors to facilitate interpretation and maximise the explained variance. Once the PC variables were obtained, canonical discriminant analysis was carried out to classify the samples. A stepwise model analysis using a significance level of 0.05 as the variable entry criterion was applied for the discriminant procedure. The leave-one-out cross-validation method was used to validate the model. 


\subsubsection{Canonical Discriminant Analysis}

Canonical discriminant analysis method was developed to classify the animals into the different slaughter ages and finishing diets. Discriminant analysis was developed including the medium spectroscopy wavelengths, and it was conducted using stepwise model analysis, which performed the best-subset selection of the quantitative predictor by a procedure of entrance-remove of variables in the model. The significant level of a variable to enter in the model was 0.05 .

\section{Results}

\subsection{Physicochemical and Sensory Description of Longissimus Thoracis Et Lumborum Muscle of Foal Meat}

Table 1 shows a description of foal meat in terms of composition and quality according to the slaughter age (SA) and finishing diet (FD). No interactions (SAxFD) were found $(p<0.05)$ on any of the parameters evaluated, except for ash, $\mathrm{L}^{*}, \mathrm{~b}^{*}, \mathrm{C}^{*}, \mathrm{~h}^{*}$ and WHC as reported by Domínguez et al. [11] in these same animals. In terms of chemical composition, the most noteworthy point is the lower moisture and more than twice the total lipids content presented by the $26 \mathrm{M}$ samples in contrast to the $13 \mathrm{M}$ samples $(p<0.001 ; p<0.001$; respectively). Fatty acids are generally different depending on slaughter age $(p<0.001)$, but not on finishing diet $(p>0.05)$. According to RGB values, all of them were higher in $26 \mathrm{M}$ and LC than in 13M samples and SC samples $(p<0.001$; respectively). Regarding CIELab colour space, the $26 \mathrm{M}$ samples showed lower $\mathrm{L}^{*}(p<0.001)$ and higher $\mathrm{a}^{*}(p<0.001)$ and $\mathrm{C}^{*}$ values $(p<0.001)$ than the $13 \mathrm{M}$ samples. With regard to the FD effect, the SC samples seemed to have higher $\mathrm{L}^{*}$ and lower $\mathrm{a}^{*}, \mathrm{~b}^{*}$ values than the LC samples $(p<0.01 ; p<0.01 ; p<0.05$, respectively). Regarding WBSF, the $26 \mathrm{M}$ samples presented higher shear force $(\mathrm{N})$ than the $13 \mathrm{M}$ samples $(p<0.05)$. As for the FD effect, the meat from the SC group showed higher values of shear force $(\mathrm{N})$ than that from the LC group $(p<0.05)$. Sensory attributes evaluated by consumers showed that meat from $13 \mathrm{M}$ foals showed higher tenderness $(p<0.001)$ and juiciness $(p<0.05)$ values than $26 \mathrm{M}$ samples. Thus, it can be stated that the differences due to finishing diet were less relevant than the differences due to slaughter age.

Regarding the relationship between physicochemical and sensory variables, the most remarkable correlations were found between the overall appraisal with tenderness and juiciness $(r=0.89, r=0.87$, respectively; $p>0.01)$. Moisture was positively correlated to tenderness $(r=0.38 ; p>0.01)$ and overall appraisal $(r=0.31 ; p>0.05)$, whereas total lipids content was negatively correlated to tenderness $(r=-0.40 ; p>0.01)$ and juiciness $(r=-0.35 ; p>0.05)$. All colour variables from the image analyses (RGB) and the CIELab system were negatively correlated to overall appraisal $(p>0.05)$. 
Table 1. Physicochemical and sensory description of Longissimus thoracis et lumborum muscle from Galician Mountain x Burguete crossbred foals slaughtered at 13 and 26 months of age $(13 \mathrm{M}, 26 \mathrm{M})$ and supplemented with standard and linseed concentrate $(\mathrm{SC}, \mathrm{LC})(n=46)$. Mean plus standard deviation and coefficient of variation $(\mathrm{CV} \%)$.

\begin{tabular}{|c|c|c|c|c|c|c|c|c|}
\hline & \multicolumn{4}{|c|}{ Slaughter Age } & \multicolumn{4}{|c|}{ Finishing Diet } \\
\hline & $13 \mathrm{M}$ & $\mathrm{CV} \%$ & $26 M$ & $\mathrm{CV} \%$ & SC & $\mathrm{CV} \%$ & LC & CV\% \\
\hline \multicolumn{9}{|l|}{ Chemical composition } \\
\hline Moisture (\%) & $74.5 \pm 0.15$ & 0.2 & $72.6 \pm 0.28$ & 0.4 & $73.9 \pm 0.27$ & 0.4 & $72.1 \pm 0.33$ & 0.5 \\
\hline Protein (\%) & $22.5 \pm 0.19$ & 0.8 & $22.7 \pm 0.19$ & 0.8 & $22.6 \pm 0.18$ & 0.8 & $23.2 \pm 0.21$ & 0.9 \\
\hline Ash $(\%)$ & $1.26 \pm 0.02$ & 0.0 & $1.38 \pm 0.03$ & 2.4 & $1.30 \pm 0.03$ & 2.3 & $1.17 \pm 0.03$ & 2.4 \\
\hline Total lipids content (\%) & $0.37 \pm 0.08$ & 14.0 & $1.82 \pm 0.16$ & 9.3 & $0.74 \pm 0.22$ & 18.3 & $1.61 \pm 0.14$ & 12.1 \\
\hline Total collagen (g/100 g meat) & $0.36 \pm 0.04$ & 11.1 & $0.44 \pm 0.05$ & 11.4 & $0.40 \pm 0.01$ & 2.5 & $0.40 \pm 0.11$ & 27.5 \\
\hline Soluble collagen (\%TCa) & $4.11 \pm 0.58$ & 14.1 & $2.39 \pm 0.63$ & 26.4 & $3.40 \pm 0.87$ & 25.6 & $3.11 \pm 0.87$ & 28.0 \\
\hline $\mathrm{pH}$ & $5.61 \pm 0.02$ & 0.4 & $5.66 \pm 0.02$ & 0.4 & $5.56 \pm 0.02$ & 0.4 & $5.58 \pm 0.02$ & 0.4 \\
\hline Water Holding Capacity & $23.3 \pm 0.61$ & 2.8 & $22.7 \pm 0.44$ & 1.9 & $20.2 \pm 0.41$ & 1.8 & $22.7 \pm 0.60$ & 2.8 \\
\hline Deoxymyoglobin $(\mathrm{DMb})(\%)$ & $25.1 \pm 5.11$ & 20.4 & $22.4 \pm 13.44$ & 60.0 & $23.2 \pm 8.64$ & 37.2 & $24.3 \pm 7.84$ & 32.3 \\
\hline Metmyoglobin (MMb) (\%) & $16.9 \pm 9.63$ & 57 & $22.0 \pm 5.91$ & 26.9 & $18.9 \pm 3.23$ & 17.1 & $20.0 \pm 5.62$ & 28.1 \\
\hline Oxymyoglobin $(\mathrm{OMb})(\%)$ & $58.0 \pm 8.14$ & 14.0 & $55.7 \pm 11.21$ & 20.1 & $57.9 \pm 7.84$ & 13.5 & $55.8 \pm 9.69$ & 17.4 \\
\hline \multicolumn{9}{|l|}{ Fatty acids (g/100 g) } \\
\hline Stearic acid & $7.21 \pm 0.20$ & 2.8 & $5.10 \pm 0.19$ & 3.7 & $6.12 \pm 0.30$ & 4.9 & $6.09 \pm 0.29$ & 4.8 \\
\hline Oleic acid & $23.0 \pm 1.03$ & 4.5 & $30.8 \pm 0.88$ & 2.9 & $25.5 \pm 1.39$ & 5.5 & $28.6 \pm 1.03$ & 3.6 \\
\hline Linoleic acid & $18.4 \pm 0.85$ & 4.6 & $11.9 \pm 0.74$ & 6.2 & $15.9 \pm 1.16$ & 7.3 & $14.1 \pm 0.88$ & 6.2 \\
\hline Linolenic acid & $11.1 \pm 0.37$ & 3.3 & $11.9 \pm 0.59$ & 5.0 & $11.1 \pm 0.53$ & 4.8 & $11.8 \pm 0.48$ & 4.1 \\
\hline Arachidonic acid & $1.73 \pm 0.12$ & 6.9 & $0.99 \pm 0.08$ & 8.1 & $1.48 \pm 0.14$ & 9.5 & $1.20 \pm 0.11$ & 9.2 \\
\hline Vaccenic acid & $0.05 \pm 0.01$ & 20.0 & $0.03 \pm 0.00$ & 0.00 & $0.04 \pm 0.01$ & 25.0 & $0.04 \pm 0.00$ & 0.0 \\
\hline Eicosapentaenoic acid (EPA) & $0.97 \pm 0.08$ & 8.3 & $0.37 \pm 0.03$ & 8.1 & $0.73 \pm 0.09$ & 12.3 & $0.58 \pm 0.07$ & 12.1 \\
\hline Docosapentaenoic acid (DPA) & $1.81 \pm 0.10$ & 5.5 & $0.92 \pm 0.07$ & 7.6 & $1.48 \pm 0.14$ & 9.5 & $1.21 \pm 0.12$ & 9.9 \\
\hline Docosahexaenoic acid (DHA) & $0.48 \pm 0.03$ & 6.3 & $0.21 \pm 0.02$ & 9.5 & $0.38 \pm 0.04$ & 10.5 & $0.29 \pm 0.03$ & 10.3 \\
\hline Total n-3 Polyunsaturated fatty acids (PUFAs) & $14.9 \pm 0.35$ & 2.4 & $13.8 \pm 0.60$ & 4.3 & $14.2 \pm 0.58$ & 4.1 & $14.4 \pm 0.45$ & 3.1 \\
\hline Total n-6 Polyunsaturated fatty acids (PUFAs) & $21.1 \pm 1.00$ & 4.7 & $13.6 \pm 0.84$ & 6.2 & $18.3 \pm 1.35$ & 7.4 & $16.1 \pm 1.03$ & 6.4 \\
\hline
\end{tabular}


Table 1. Cont

\begin{tabular}{|c|c|c|c|c|c|c|c|c|}
\hline & \multicolumn{4}{|c|}{ Slaughter Age } & \multicolumn{4}{|c|}{ Finishing Diet } \\
\hline & $13 \mathrm{M}$ & $\mathrm{CV} \%$ & $26 M$ & $\mathrm{CV} \%$ & SC & $\mathrm{CV} \%$ & LC & $\mathrm{CV} \%$ \\
\hline \multicolumn{9}{|l|}{ Quality parameters } \\
\hline Red & $141.6 \pm 6.93$ & 5.0 & $161.9 \pm 9.63$ & 6.0 & $150.6 \pm 17.89$ & 11.9 & $152.9 \pm 7.42$ & 4.9 \\
\hline Green & $85.9 \pm 6.73$ & 7.8 & $98.7 \pm 5.54$ & 5.6 & $90.3 \pm 9.71$ & 10.8 & $94.3 \pm 4.15$ & 4.4 \\
\hline Blue & $99.0 \pm 8.88$ & 8.8 & $112.9 \pm 7.39$ & 6.5 & $103.2 \pm 11.81$ & 11.4 & $108.6 \pm 5.43$ & 5.0 \\
\hline $\mathrm{L}^{*}$ (Lightness) & $32.49 \pm 2.31$ & 7.1 & $28.90 \pm 3.25$ & 11.3 & $31.82 \pm 2.99$ & 9.4 & $29.57 \pm 3.36$ & 11.4 \\
\hline $\mathrm{a}^{*}$ (Redness) & $17.59 \pm 1.32$ & 7.5 & $20.35 \pm 3.15$ & 15.5 & $17.89 \pm 1.85$ & 10.3 & $20.05 \pm 3.17$ & 15.8 \\
\hline$b^{*}$ (Blue) & $10.01 \pm 1.67$ & 16.7 & $11.49 \pm 3.81$ & 33.2 & $9.92 \pm 1.83$ & 18.5 & $11.58 \pm 3.74$ & 32.3 \\
\hline C (Chroma) & $20.29 \pm 1.55$ & 7.6 & $23.46 \pm 3.51$ & 15.0 & $20.52 \pm 2.03$ & 9.9 & $23.23 \pm 4.53$ & 19.5 \\
\hline $\mathrm{h}$ (Hue angle) & $29.56 \pm 4.25$ & 14.4 & $28.79 \pm 4.98$ & 17.3 & $28.94 \pm 4.72$ & 16.3 & $29.41 \pm 4.58$ & 15.6 \\
\hline Warner-Bratzler shear force (WBSF) (Newtons) & $45.88 \pm 5.73$ & 12.5 & $53.27 \pm 5.71$ & 10.7 & $52.71 \pm 4.99$ & 9.5 & $46.44 \pm 6.73$ & 14.5 \\
\hline Tenderness & $5.76 \pm 0.64$ & 11.1 & $5.03 \pm 0.88$ & 17.5 & $5.44 \pm 0.60$ & 11.0 & $5.35 \pm 0.55$ & 10.3 \\
\hline Juiciness & $5.61 \pm 0.63$ & 11.2 & $5.14 \pm 0.85$ & 16.5 & $5.45 \pm 0.63$ & 11.6 & $5.31 \pm 0.74$ & 13.9 \\
\hline Overall appraisal & $5.65 \pm 0.45$ & 8.0 & $5.36 \pm 0.61$ & 11.4 & $5.60 \pm 0.53$ & 9.5 & $5.41 \pm 0.69$ & 12.8 \\
\hline
\end{tabular}

Some of the data were previously reported by Domínguez et al. [11] (License Number 4811250281534). 
3.2. Calibration and Validation Models to Predict the Chemical Composition and Quality Parameters of Foal Meat

In order to look into the intrinsic properties of foal meat, regression models were built based on the two spectrum ranges $\left(3200-2500 \mathrm{~cm}^{-1}\right.$ and $\left.2300-980 \mathrm{~cm}^{-1}\right)$ to estimate the chemical composition and quality parameters of the samples analysed from the spectral information.

Figure 1 shows the typical spectrum characteristics obtained by FT-MIR analysis in samples from 13 and 26-month-old foals (13M, 26M) and supplemented with standard and linseed concentrate (SC, SL). Figure 1a, represents the section from $3000 \mathrm{~cm}^{-1}$ to $2700 \mathrm{~cm}^{-1}$ and Figure $1 \mathrm{~b}$ represents the region from $1900 \mathrm{~cm}^{-1}$ to $750 \mathrm{~cm}^{-1}$.

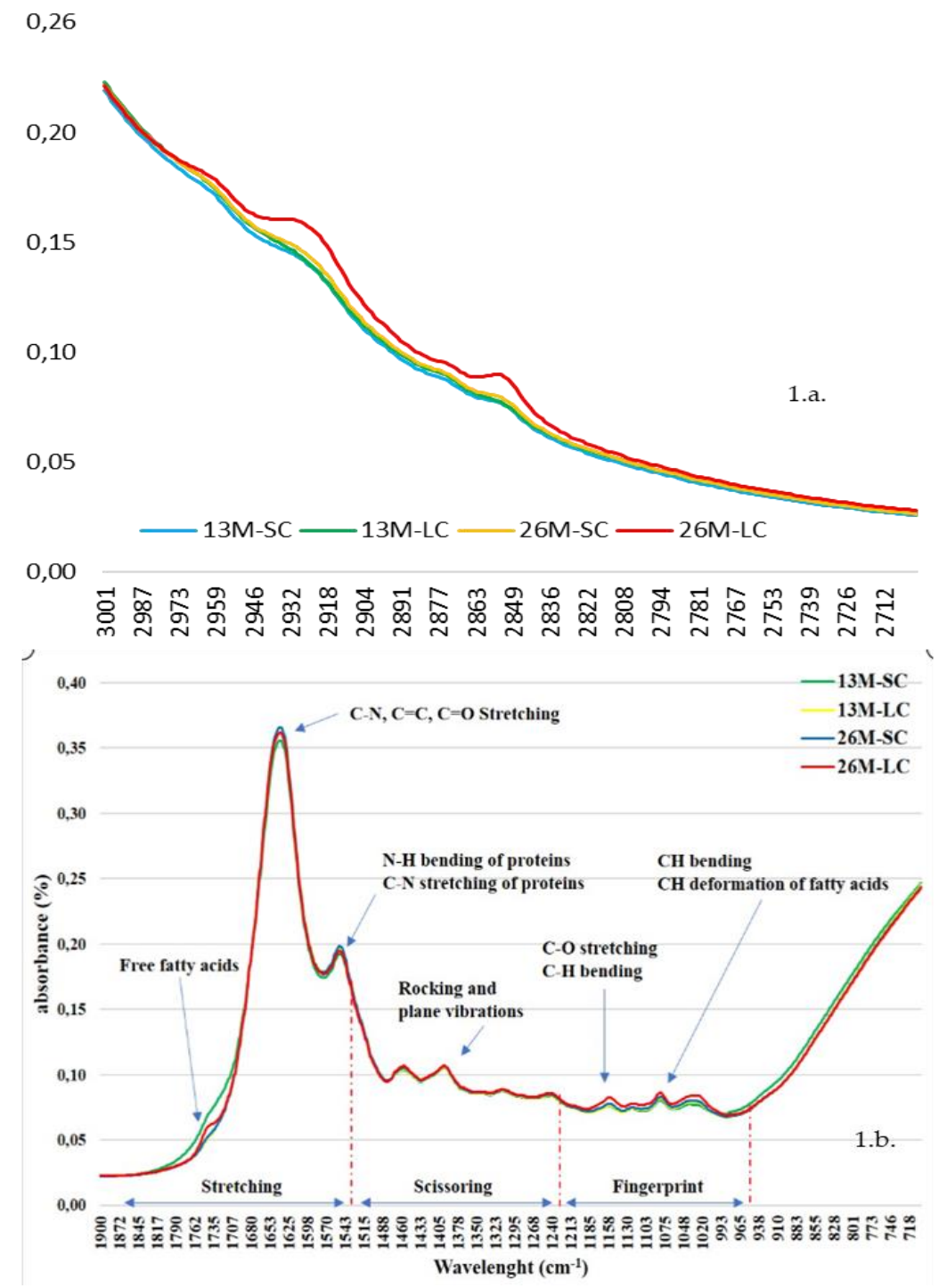

Figure 1. Spectral characteristics of the samples from 13- and 26-month-old foals (13M, 26M) and supplemented with standard and linseed concentrate (SC, SL). Range selected from $3000-2700 \mathrm{~cm}^{-1}$ (a) and from 1900-750 $\mathrm{cm}^{-1}$ (b) according to Lozano et al. [3].

Based on the obtained spectrum data, Table 2 shows mathematical treatments and wavelengths for each calibration and validation equation according to chemical composition, fatty acid profile, and quality parameters, respectively. 
Table 2. Results of the PLS regression models for the MIR data matrix of meat composition and quality from 13- and 26-month-old Galician Mountain x Burguete crossbred foals (13M, 26M) supplemented with standard and linseed concentrate.

\begin{tabular}{|c|c|c|c|c|c|c|c|c|c|c|}
\hline & \multicolumn{6}{|c|}{ Calibration } & \multicolumn{4}{|l|}{ Validation } \\
\hline & $n^{\mathrm{a}}$ & $p^{\mathrm{b}}$ & $\operatorname{Rc}^{2}(\%)^{c}$ & RMSEC $^{d}$ & RPD & $\operatorname{Rv}^{2}(\%)^{\mathrm{e}}$ & RMSECV $\mathrm{f}$ & RPD $^{g}$ & Treatment & Selected Regions $\left(\mathrm{cm}^{-1}\right)$ \\
\hline \multicolumn{11}{|l|}{ Chemical Composition } \\
\hline Moisture & 41 & 9 & 93.67 & 0.34 & 3.97 & 81.57 & 0.53 & 2.33 & Max. and min. normalisation & 3278-2918; 1839-1478; 1119-759 \\
\hline Protein & 42 & 1 & 30.36 & 0.75 & 1.20 & 22.71 & 0.78 & 1.14 & Max. and min. normalisation & 3998-3637; 1839-1478; 1119-399 \\
\hline Ash & 42 & 5 & 97.92 & 0.02 & 6.36 & 40.55 & 0.09 & 1.30 & 2nd derivate & $3278-2918 ;$; $2198-1838$ \\
\hline Total lipids content & 38 & 5 & 26.30 & 0.85 & 1.16 & 65.99 & 0.46 & 1.72 & 2nd derivate & 2559-1838; 1479-1118 \\
\hline Total collagen & 40 & 8 & 98.12 & 0.01 & 7.39 & 70.65 & 0.04 & 1.85 & 1st derivate $+\mathrm{MSCh}$ & 3638-3277; 1479-1118 \\
\hline Soluble collagen & 45 & 1 & 9.78 & 2.67 & 1.05 & 0.615 & 2.72 & 1.00 & MSC & 2198-1838 \\
\hline $\mathrm{pH}$ & 40 & 1 & 31.19 & 0.07 & 1.21 & 22.39 & 0.07 & 1.14 & Removal of constant slope & $1479-1118$ \\
\hline Water Holding Capacity (WHC) & 37 & 1 & 29.88 & 1.56 & 1.19 & 20.03 & 1.60 & 1.13 & Removal of constant slope & 759-399 \\
\hline Deoxymyoglobin DMb & 46 & 10 & 97.88 & 6.88 & 1.55 & 25.78 & 8.02 & 1.16 & 2nd derivate & 3278-2918; 1839-1118 \\
\hline Metmyoglobin (MMb) & 45 & 3 & 35.31 & 5.21 & 1.24 & 21.63 & 5.48 & 1.13 & 1st derivate + MSC & 1839-1478 \\
\hline Oxymyoglobin $(\mathrm{OMb})$ & 46 & 3 & 29.23 & 8.27 & 1.19 & 16.25 & 8.58 & 1.09 & MSC & 1839-1118; 759-399 \\
\hline \multicolumn{11}{|l|}{ Fatty acids } \\
\hline Stearic acid & 42 & 10 & 97.73 & 0.23 & 6.63 & 61.77 & 0.79 & 1.62 & 1st derivate $+\mathrm{SNV}$ & 3638-3277; 2559-2198; 1839-1118 \\
\hline Oleic acid & 43 & 10 & 96.70 & 0.28 & 5.51 & 60.07 & 0.83 & 1.59 & 1st derivate $+\mathrm{SNV}$ & 3638-3277; 2559-2198; 1839-1118 \\
\hline Linoleic acid & 38 & 8 & 88.13 & 1.83 & 2.90 & 55.49 & 3.15 & 1.50 & 1st derivate $+\mathrm{SNV}$ & $3638-3277 ; 1839-1118$ \\
\hline Linolenic acid & 43 & 7 & 98.47 & 0.32 & 8.07 & 38.36 & 1.82 & 1.27 & 2nd derivate & $3278-2918 ; 2559-2198 ; 1119-759$ \\
\hline Arachidonic acid & 40 & 9 & 97.03 & 0.12 & 5.80 & 77.67 & 0.29 & 2.12 & MSC & 2919-2558; $1119-759$ \\
\hline Vaccenic acid & 43 & 5 & 93.70 & 0.01 & 3.98 & 67.11 & 0.01 & 1.74 & 1st derivate $+\mathrm{SNVi}$ & 2559-2199 \\
\hline Docosapentaenoic acid (DPA) & 43 & 10 & 97.03 & 0.12 & 5.80 & 76.39 & 0.29 & 2.06 & 1st derivate $+\mathrm{SNV}$ & 3638-3277; 2919-2558; 1839-1118 \\
\hline Eicosapentaenoic acid (EPA) & 42 & 10 & 87.47 & 0.13 & 2.83 & 54.64 & 0.22 & 1.50 & None & $3104-2501 ; 2130-893$ \\
\hline Docosahexaenoic acid (DHÁ) & 43 & 3 & 97.03 & 0.12 & 5.80 & 76.39 & 0.03 & 2.06 & 1st derivate $+\mathrm{SNV}$ & 3638-3277; 2919-2558; 1839-1118 \\
\hline Total n-3 Polyunsaturated fatty acids (PUFAs) & 39 & 4 & 90.73 & 0.58 & 3.29 & 41.19 & 1.37 & 1.30 & 2nd derivate & $3278-2918 ; 2559-2198$ \\
\hline Total n-6 Polyunsaturated fatty acids (PUFAs) & 40 & 8 & 94.87 & 1.46 & 4.42 & 73.89 & 2.90 & 1.96 & MSC & 2919-2558; 1119-759 \\
\hline \multicolumn{11}{|l|}{ Quality parameters } \\
\hline Red & 42 & 7 & 98.06 & 2.53 & 7.18 & 58.47 & 10.5 & 1.55 & 1st derivate + MSC & 3998-3637; 1119-759 \\
\hline Green & 43 & 7 & 91.65 & 3.24 & 3.46 & 70.32 & 5.55 & 1.84 & 1st derivate + MSC & 3998-3637; 2198-1118 \\
\hline Blue & 39 & 8 & 96.03 & 2.77 & 5.02 & 73.63 & 6.26 & 1.95 & 1st derivate + MSC & 3998-3637; 2198-1118 \\
\hline $\mathrm{L}^{*}$ (Lightness) & 46 & 1 & 6.80 & 2.59 & 1.04 & 5.28 & 2.69 & 1.00 & Max. and min. normalisation & $3090-2497 ; 2300-980$ \\
\hline $\mathrm{a}^{*}$ (Redness) & 46 & 1 & 25.70 & 1.76 & 1.16 & 15.85 & 1.83 & 1.09 & Max. and min. normalisation & $3200-2500 ; 2300-980$ \\
\hline $\mathrm{b}^{*}$ (Blue) & 46 & 1 & 31.01 & 2.16 & 1.20 & 21.55 & 2.25 & 1.13 & Max. and min. normalisation & $3200-2500 ; 2300-980$ \\
\hline C (Chroma) & 46 & 1 & 36.74 & 1.78 & 1.26 & 22.60 & 1.93 & 1.14 & Max. and min. normalisation & $3200-2500 ; 2300-980$ \\
\hline $\mathrm{h}$ (Hue angle) & 46 & 1 & 11.71 & 4.06 & 1.06 & 4.49 & 4.13 & 1.02 & Max. and min. normalisation & $3200-2500 ; 2300-980$ \\
\hline Warner-Bratzler shear force (WBSF) & 40 & 3 & 44.62 & 10.3 & 1.34 & 25.7 & 11.6 & 1.60 & 1st derivate $+\mathrm{SNV}$ & $1119-759$ \\
\hline Tenderness & 46 & 1 & 36.17 & 0.49 & 1.24 & 27.41 & 0.50 & 1.17 & Max. and min. normalisation & $3200-2500$ \\
\hline Juiciness & 46 & 1 & 18.91 & 0.56 & 1.12 & 8.04 & 0.58 & 1.04 & Max. and min. normalisation & $3200-2500$ \\
\hline Overall appraisal & 46 & 1 & 29.49 & 0.39 & 1.19 & 23.89 & 0.39 & 1.05 & 1st derivate & $3200-2500$ \\
\hline
\end{tabular}

MSC: Multiplicative Scatter Correction; SNV: Vectorial Normalization; $h$ multiplicative scattering correction; i standard normal variate. a: number of samples used in calibration, $\mathrm{b}$ : number of terms included in the equation, c: coefficient of determination for calibration, d: root mean square error of calibration, e: coefficient of determination for cross-validation; f: root mean square error of cross-validation; g: ratio of prediction to deviation; 
In Table 2, it is shown that moisture and total collagen showed coefficient of determination for validation $\left(\mathrm{Rv}^{2}\right)$ higher than $70 \%$, Total lipids content reached higher coefficient of determination for validation $\left(\mathrm{Rv}^{2}\right)(66 \%)\left(\mathrm{Rc}^{2}\right)$ compared to calibration $(76.30 \%)$. With regard to pigment content $(\%)$, oxymyoglobin $(\mathrm{OMb})$, deoxymyoglobin $(\mathrm{DMb})$, and metmyoglobin $(\mathrm{MMb})$ reached low validation coefficients $\left(\mathrm{Rv}^{2}<26 \%\right)$. Nevertheless, the three of them seemed to be related to, at least, the wavelength range $1839-1478 \mathrm{~cm}^{-1}$. Finally, the rest of the variables did not reach $26 \%$, except for ash content (40.55\%). According to the fatty acids, $\mathrm{Rv}^{2}$ for linoleic, linolenic, EPA and omega-3 polyunsaturated fatty acids did not reach $60 \%$, in spite of reaching $\mathrm{Rc}^{2}$ values over $88 \%$. The best prediction models, with $\mathrm{Rv}^{2}$ over $75 \%$, were obtained for arachidonic, DPA, DHA (with RPD values over 2), and omega-6 polyunsaturated fatty acids (with an RPD value close to 2). The most repeated selected wavelength ranges were $3838-3277,2919-2558$, and $1839-1118 \mathrm{~cm}^{-1}$. The best treatments were first derivate plus standard normal variate (SNV) and multiplicative scatter correction (MSC).

Regarding colour, RGB variables reached high values for $\mathrm{Rc}^{2}$ (over 90\%) and $\mathrm{Rv}^{2}$ (over $60 \%$, with the exception of red), whereas the most commonly studied colour coordinates $\left(\mathrm{L}^{*}, \mathrm{a}^{*}, \mathrm{~b}^{*}, \mathrm{C}^{*}\right.$, $h^{*}$ ) reached both calibrations and validation coefficients below $40 \%$ and $22 \%$, respectively, being $h^{*}$ the worst predicted variable $(4.49 \%)$. The selected wavelength ranges for RGB colour variables were 3998-3637 and 2198-1118 $\mathrm{cm}^{-1}$, and the first derivate + MSC was used as prediction treatment for most of the cases. On the other hand, no enclosed wavelength range were described for $L^{*}, a^{*}, b^{*}, C^{*}$ and $h^{*}$.

For WBSF, the prediction results were poor $\left(\mathrm{Rv}^{2}=25.70 \%\right)$. Likewise, predictability for all sensory attributes were poor with the highest $\mathrm{Rv}^{2}$ and $\mathrm{Rc}^{2}$ values being $27.21 \%$ and $36.17 \%$, respectively. The three sensory variables were negatively correlated to WBSF (tenderness; $r=-0.82, p<0.01$; juiciness; $r=-0.89, p<0.01$; overall appraisal; $r=-0.66, p<0.05)$ and the low accuracy of WBSF prediction could be reflected in the sensory attributes. Besides, WBSF was positively correlated with cooking losses [11], and meat moisture was also highly and negatively related to intramuscular fat content $(r=-0.89 ; p<0.01)$.

\subsection{Principal Component and Discriminant Analyses}

After the results obtained from the chemometric analysis, three different wavelengths ranges were selected according to the prediction accuracy for chemical composition, the studied fatty acids, and the quality parameters. These were: $3278-2918 \mathrm{~cm}^{-1}$ for the chemical composition variables group, $2919-2558 \mathrm{~cm}^{-1}$ for the fatty acids group and $2198-1118 \mathrm{~cm}^{-1}$ for the quality parameters group. Taking these ranges into account, canonical discriminant analyses were again carried out in order to improve the first classification obtained before developing the calibration and validation models (Table 3). From these results, the best wavelength range in order to classify samples according to slaughter age and finishing diet is the one which better predicts the quality parameters: $2198-1118 \mathrm{~cm}^{-1}$. These results showed that for slaughter age, samples were classified with an accuracy around $78.3 \%$ whereas regarding finishing diet, samples were classified with an accuracy around $71.8 \%$. Even if just one classification result was higher than $80 \%$, there are three results close to $80 \%(77.3 \%, 79.2 \%$, and $78.3 \%)$ that make MIR an interesting alternative method. 
Table 3. Classification matrix from MIR spectrum of 13- and 26-month-old Galician Mountain x Burguete crossbred foals (13M, 26M) and supplemented with standard and linseed concentrate (SC, LC). Discriminant analyses results after selecting the most suitable wavelength range from the prediction models.

\begin{tabular}{|c|c|c|}
\hline Spectral Wavelength & \multicolumn{2}{|c|}{ Classify Into } \\
\hline \multicolumn{3}{|l|}{ Range $3278-2918 \mathrm{~cm}^{-1}$} \\
\hline & $13 \mathrm{M}$ & $26 \mathrm{M}$ \\
\hline 13-month-old (\%) & 63.6 & 36.4 \\
\hline 26-month-old (\%) & 29.2 & 70.8 \\
\hline & SC & LC \\
\hline Standard Concentrate (\%) & 56.5 & 43.5 \\
\hline Linseed Concentrate $(\%)$ & 34.8 & 65.2 \\
\hline \multicolumn{3}{|l|}{ Range $2919-2558 \mathrm{~cm}^{-1}$} \\
\hline & $13 \mathrm{M}$ & $26 \mathrm{M}$ \\
\hline 13-month-old (\%) & 86.4 & 13.6 \\
\hline 26-month-old (\%) & 37.5 & 62.5 \\
\hline & SC & $\mathrm{LC}$ \\
\hline Standard Concentrate (\%) & - & - \\
\hline Linseed Concentrate (\%) & - & - \\
\hline \multicolumn{3}{|l|}{ Range $2198-1118 \mathrm{~cm}^{-1}$} \\
\hline \multirow{4}{*}{$\begin{array}{l}\text { 13-month-old (\%) } \\
26 \text {-month-old (\%) }\end{array}$} & $13 \mathrm{M}$ & $26 \mathrm{M}$ \\
\hline & 77.3 & 22.7 \\
\hline & 20.8 & 79.2 \\
\hline & SC & $\mathrm{LC}$ \\
\hline Standard Concentrate (\%) & 78.3 & 21.7 \\
\hline Linseed Concentrate $(\%)$ & 34.8 & 65.2 \\
\hline
\end{tabular}

-: Any possible samples' classification according to finishing diet with that selected range.

\section{Discussion}

Regarding the spectra characteristics of the samples in the medium infrared, Lozano et al. [3] described the two most important spectra ranges as far as foal meat is concerned: $3200-2500 \mathrm{~cm}^{-1}$ and $2300-980 \mathrm{~cm}^{-1}$. These two sections are shown in Figure 1a and in Figure $1 \mathrm{~b}$ for meat samples from $13 \mathrm{M}$ and 26M foals supplemented with SC and LC concentrate samples (13M-SC, 13M-LC, 26M-SC, 26M-LC). Both ranges have been slightly widened not to lose possible wavelength which could show some differences between each group. The region from $3000 \mathrm{~cm}^{-1}$ to $2700 \mathrm{~cm}^{-1}$ (Figure 1a) is the one of hydrogen's stretching related to $-\mathrm{C}-\mathrm{H}$ stretching vibration, involving double bounds $=\mathrm{C}-\mathrm{H}$ and aliphatic $\mathrm{CH}_{3}$ and $\mathrm{CH}_{2}$ [21,22]. It is shown that 26M-LC samples described higher absorbance peaks than 13M-SC/LC and 26M-SC between 2990 and $2800 \mathrm{~cm}^{-1}$. This means that asymmetric and symmetric stretching vibrations of -C-H of aliphatic $\mathrm{CH}_{3}$ at 2959 and $2873 \mathrm{~cm}^{-1}$ were taking place more intensely than in the other groups. Moreover, the absorbance difference at 2925 and $2851 \mathrm{~cm}^{-1}$ (peaks related to asymmetric and symmetric stretching vibrations of $-\mathrm{C}-\mathrm{H}$ of aliphatic $\mathrm{CH}_{2}$ ) between $26 \mathrm{M}-\mathrm{LC}$ and the others 3 groups, was even higher, and thus more intense. Domínguez et al. [11] showed that $26 \mathrm{M}$ foals' samples and those from foals supplemented with linseed concentrate presented a higher amount of monounsaturated fatty acids and reached higher total lipids content (Table 2). This higher amount of aliphatic $\mathrm{CH}_{3}$ and $\mathrm{CH}_{2}$ compounds define larger fatty acids chains, indirectly represented with a higher absorbance.

The region showed in Figure 1b, involves double bond's stretching $\left(1750-1650 \mathrm{~cm}^{-1}\right)$, other deformations and bendings $\left(1500-1200 \mathrm{~cm}^{-1}\right)$ and the called "fingerprint range" $\left(1200-950 \mathrm{~cm}^{-1}\right)[3,21,22]$. 
The 13M-SC samples, which presented a higher percentage of saturated and polyunsaturated fatty acids $(35.2 \mathrm{~g} / 100 \mathrm{~g}$ vs. $33.4 \mathrm{~g} / 100 \mathrm{~g})$ [14] and higher lipid oxidation than the rest of groups ( $0.40 \mathrm{vs} .0 .36 \mathrm{mg}$ $\mathrm{MDA} / \mathrm{kg}$ fresh meat) (data not shown), showed a higher absorbance from 1800 to $1700 \mathrm{~cm}^{-1}$. Bands at $1742 \mathrm{~cm}^{-1}$ are related to triglycerides and free fatty acids. Vlachos et al. [23] explained that an oxidation of fatty acids is likely to happen close to $1700 \mathrm{~cm}^{-1}$, and that the accurate peak position and intensity would depend on the fatty acid composition. Thus, it might be possible that the higher absorbance obtained for 13M-SC samples, was linked to the high amount of polyunsaturated fatty acids and a possible lipid oxidation.

Bonds of N-H, C=C, C-N, and the combination of N-H with C-H (Amides II) are typical of protein amino acids and appear at bands 1657 and $1542 \mathrm{~cm}^{-1}$ [3]. Figure 1 does not show any difference in the absorbance although it seems to be slightly higher in 26M-SC foal meat samples. Along the fingerprint range, a smooth absorbance increase can be seen in the 26M-LC foal meat samples, but not determinant. This region is related to stretching vibrations of the $\mathrm{C}-\mathrm{O}$ bond stretching vibration and the $\mathrm{C}-\mathrm{H}$ bond bending vibration and the peak at $1117 \mathrm{~cm}^{-1}$ is assigned to bending and twisting vibration of the fatty acids [24]. Correlations help to better understand the bands' changes due to different vibrations. The absorbance $\sim 2959 \mathrm{~cm}^{-1}$ was positively correlated to the peak $\sim 2925 \mathrm{~cm}^{-1}(0.78), \sim 2837 \mathrm{~cm}^{-1}$ (0.94), $\sim 2851 \mathrm{~cm}^{-1}$ (0.74), $1658 \mathrm{~cm}^{-1}(0.81), \sim 1542 \mathrm{~cm}^{-1}$ (0.67) and $\sim 117 \mathrm{~cm}^{-1}$ (0.73). And these wavenumbers are related to typical vibration modes of the lipids' fatty acids and proteins (C-H bonds). A weak and negative correlation between 2959 and $1742 \mathrm{~cm}^{-1}$ was found $\left(-0.38^{* *}\right)$. This means that the stretching vibration of carbonyl bond of esters and free fatty acids [3] related to this peak is different from the vibration way at $2959 \mathrm{~cm}^{-1}$. Another example of different vibration is better understood by the positive correlation found between the peak at $\sim 1117 \mathrm{~cm}^{-1}$ and $\sim 2925\left(0.88^{* *}\right), \sim 2873\left(0.88^{* *}\right)$ and $\sim 2851 \mathrm{~cm}^{-1}\left(0.90^{* *}\right)$. All these peaks are related to vibration of the fatty acids. But $\sim 1117 \mathrm{~cm}^{-1}$ is assigned to bending and twisting vibration whereas the other ones are related to stretching vibrations.

The lack of MIR spectroscopy studies dealing with meat composition and meat quality makes necessary the comparison of the obtained results with studies of NIR spectroscopy, although the spectra range is not the same. It should be explained that the ratio of prediction to deviation (RPD) is noticeably poor with regard to validation results, except for moisture (2.33). High quality moisture models have been reported in the literature, with coefficients of determination higher than 0.70 in NIR [5] This means that the regression models have a low accuracy to predict different chemical composition parameters of foal meat. The prediction model for protein had a low $\mathrm{Rv}^{2}(22.71 \%)$. Difficulties in predicting meat protein content have been previously reported in beef $[6,25]$ with NIR spectroscopy. One of the causes of the low accuracy of protein prediction in meat could be related to the analytical differences between the Kjeldahl determination (which measures nitrogen) and the MIR/NIR techniques (which measures protein bonds) [26]. Another reason could be related to the MIR spectra record fundamental molecular vibrations, which can be more easily affected by multiple interferences [27]. Nevertheless, better results were obtained when applying MIR to the prediction of fat and protein in beef [3]. On the contrary, when comparing the results with Ripoll et al. [5] similar results were observed for chemical composition with NIR spectroscopy. This fact could be due to the more developed beef production systems compared to foal production systems, which could favour better regression results. For both moisture and protein content, the maximum and minimum normalisation treatment were used, being $1839-1478 \mathrm{~cm}^{-1}$ and $1119-759 \mathrm{~cm}^{-1}$ the wavelength ranges employed.

Higher validation values were reported in beef $(76 \%)$ [5] or lamb (73\%) [28] with NIR spectroscopy. This could be due to the fact that measurements were taken on the intact sample instead of on a homogenised sample. Total collagen content showed also high $\mathrm{Rv}^{2}(70.65 \%)$, far from those reported by other authors with NIR spectroscopy in beef [29]. For both total lipids and total collagen content, it must be mentioned that RPD values (1.72 and 1.85, respectively) were close to 2 , threshold which defines an acceptable regression model. In addition, in both cases the wavelength selected was $1479-1118 \mathrm{~cm}^{-1}$. These models are in concordance with the obtained spectra results and with the literature mentioned according to fatty acids [23,24]. Therefore, these results are of great practical importance and they make 
in evidence the usefulness of MIR spectroscopy technique and the need of gaining deeper knowledge on this research field. It must be mentioned as well, that the vaccenic acid (precursor of conjugated linoleic acid, CLA), reached $\mathrm{Rv}^{2}$ of $67.11 \%$ and an RPD value of 1.74 . The potential properties of CLA for human health [30] support the need of developing further studies to be able to detect it, qualitative and quantitatively.

The lack of references dealing with the estimation of colour parameters with both NIR and MIR spectroscopy makes a deeper discussion of the results more difficult.

Regarding meat texture, as stated by Ripoll et al. [5], the strong relationships between moisture, fat, and cooking losses with WBSF could explain the WBSF behaviour better than its own calibration model. Geesink et al. [31] did not obtain useful models for WBSF, owing to limited muscle variance (CV: 21\%). This fact could be another reason for the weak prediction result in the present research (ranged 10-14\%).

As reported by Ripoll et al. [5] and Andrés et al. [32] for sensory traits in beef and lamb respectively, tenderness, juiciness, and overall appraisal are hard to estimate as they are subjective judgements and their correlations to other instrumental determinations are weak. The low prediction values obtained for most of the quality parameters and consumer evaluation results could be explained by the low number of samples employed. Perhaps, these prediction models would be better with a higher number of samples [3]. Besides, foal meat is characterised by its heterogeneity, and, what is more, it suffers rapid internal composition changes [10] that could highly affect the spectra results. These results could be also due to the interferences related to the homogeneity and particle size of the sample and its performance [33].

After applying discriminant analysis based on the spectra ranges $3200-2500 \mathrm{~cm}^{-1}$ and $2300-980 \mathrm{~cm}^{-1}$ for classifying the samples according to slaughter age or finishing diet, the obtained results showed lower values in the present study than those found by Xing et al. [34] in intact pork meat (85\% accuracy) and Juárez et al. [35] who classified six sheep breeds ( $83 \%$ accuracy) by visible spectroscopy. These results may let infer that the variables obtained from the multivariate statistical treatment, which involved the most relevant spectra data, are mainly related to different characteristics due to the slaughter age than due to finishing diet. Moreover, according to the relationship appreciated in the spectra between different wavelengths and the fatty acids, it could be highlighted that the total lipid contents would be one of the most evident causes why $13 \mathrm{M}$ and $26 \mathrm{M}$ foals are different.

\section{Conclusions}

The MIR spectra obtained in the present research showed some remarkable differences mainly due to the fat and the fatty acid composition. Prediction models were accurate for moisture, collagen, and lipids, most of the fatty acids (chemical composition) and for the RGB colour coordinates (quality parameters). Classifications by discriminant analysis showed good results after the use of regression treatments delimiting the range of the spectrum to $2198-1118 \mathrm{~cm}^{-1}$ and coinciding with the wavelengths in which a large number of protein and fatty acid bonds are recognised.

From a commercial point of view, and based on the obtained results, the use of MIR spectroscopy could be used to sort out meat from "old vs young" foals. Less precision was achieved according to the foals feeding. Anyway, due to the low accuracy to predict different chemical composition and sensory parameters of foal meat, and considering the potential of this technique, more studies are needed in order to improve the estimation of meat characteristics.

Since the present study intends to be a preliminary approach to know the possibilities of the application of MIR spectroscopy to the study of meat quality, for future researches it would be necessary to use a larger sample number and study other physical characteristics such as protein denaturation or sarcomere length which could help to understand changes in the bonds.

Summarising, MIR spectroscopy could be a potential alternative to traditional meat composition analytical methods but, at the present study, the obtained accuracies are low for industry application and still need to be improved. 
Author Contributions: Conceptualization, M.J.B.; Methodology K.I., M.V.S., and M.R.; Software, M.B.; Formal analysis, M.J.B. and K.I.; Investigation, M.J.B. and M.V.S.; Resources, M.B. and J.M.L.; Writing-original draft preparation, M.R.; Writing-review and editing, M.V.S., M.J.B., K.I., and J.M.L.; Project administration, M.V.S., M.J.B. and J.M.L. All authors have read and agreed to the published version of the manuscript.

Funding: This research was funded by INIA Instituto Nacional de Investigación y Tecnología Agraria y Alimentaria, grant number RTA 2012-00090-C03-01 and by the Spanish Ministerio de Ciencia, Innovación y Universidades, Project RTI2018-094475-B-I00 (MCIU/AEI/FEDER, UE).

Acknowledgments: Authors want to acknowledge Susana García from the UPNA for her support in sampling preparation and analysis.

Conflicts of Interest: The authors declare no conflict of interest.

\section{References}

1. Karoui, R.; Downey, G.; Blecker, C. Mid-Infrared Spectroscopy Coupled with Chemometrics: A Tool for the Analysis of Intact Food Systems and the Exploration of Their Molecular Structure-Quality Relationships-A Review. Chem. Rev. 2010, 10, 6144-6168. [CrossRef] [PubMed]

2. de Oliveira, G.A.; de Castilhos, F.; Renard, C.M.G.C.; Bureau, S. Comparison of NIR and MIR spectroscopic methods for determination of individual sugars, organic acids and carotenoids in passion fruit. Food Res. Int. 2014, 60, 154-162. [CrossRef]

3. Lozano, M.; Rodríguez-Ulibarri, P.; Echeverría, J.C.; Beruete, M.; Sorolla, M.; Beriain, M.J. Mid-Infrared Spectroscopy (MIR) for Simultaneous Determination of Fat and Protein Content in Meat of Several Animal Species. Food Anal. Method. 2017, 10, 3462-3470. [CrossRef]

4. Yancey, J.W.S.; Applea, J.K.; Meullenetb, F.F.; Sawyer, J.T. Consumer responses for tenderness and overall impression can be predicted by visible and near-infrared spectroscopy, Meullenet-Owens razor shear, and Warner-Bratzler shear force. Meat Sci. 2010, 85, 487-492. [CrossRef]

5. Ripoll, G.; Albertí, P.; Panea, B.; Olleta, J.L.; Sañudo, C. Near-infrared reflectance spectroscopy for predicting chemical, instrumental and sensory quality of beef. Meat Sci. 2008, 80, 697-702. [CrossRef]

6. Belaunzaran, X.; Bessa, R.J.; Lavín, P.; Mantecón, A.R.; Kramer, J.K.; Aldai, N. Horse-meat for human consumption-Current research and future opportunities. Meat Sci. 2015, 108, 74-81. [CrossRef]

7. Lorenzo, J.M.; Crecente, S.; Franco, D.; Sarriés, M.V.; Gómez, M. The effect of livestock production system and concentrate level on carcass traits and meat quality of foals slaughtered at 18 months of age. Animal 2014, 8, 494-503. [CrossRef]

8. Franco, D.; Lorenzo, J.M. Effect of muscle and intensity of finishing diet on meat quality of foals slaughtered at 15 months. Meat Sci. 2014, 96, 327-334. [CrossRef]

9. Sarriés, M.V.; Beriain, M.J. Colour and texture characteristics in meat of male and female foals. Meat Sci. 2006, 74, 738-745. [CrossRef]

10. Ruiz, M.; Sarriés, M.V.; Beriain, M.J.; Crecente, S.; Domínguez, R.; Lorenzo, J.M. Relationship between carcass traits, prime cuts and carcass grading from foals slaughtered at the age of 13 and 26 months and supplemented with standard and linseed-rich feed. Animal 2017, 12, 1084-1092. [CrossRef]

11. Domínguez, R.; Pateiro, M.; Crecente, S.; Ruiz, M.; Sarriés, M.V.; Lorenzo, J.M. Effect of linseed supplementation and slaughter age on meat quality of grazing cross-bred Galician $\mathrm{x}$ Burguete foals. J. Sci. Food Agr. 2018, 98, 266-273. [CrossRef] [PubMed]

12. Bonnet, M.; Kopp, J. Dosage du collagène dans les tissus conjonctifs, la viande et les produits carnés. Viandes Produits Carnés 1986, 7, 263-266.

13. The American Meat Science Association (AMSA). Meat color measurement guidelines. In American Meat Science Association; The American Meat Science Association (AMSA): Champaign, IL, USA, 2012.

14. Karamucki, T.; Jakubowska, M.; Rybarczyk, A.; Gardzielewska, J. The influence of myoglobin on the colour of minced pork loin. Meat Sci. 2013, 94, 234-238. [CrossRef] [PubMed]

15. Commission Internationale de l'Eclairage. Colorimetry_Part 4: CIE 1976 L $^{*} a^{*} b^{*}$ Colour Spaces; Publication CIE: Vienna, Austria, 2008.

16. Mendizabal, J.; Purroy, A.; Indurain, G.; Insausti, K. Medida del grado de veteado de la carne mediante análisis de imagen. In Estandarización de las Metodologías para Evaluar la Calidad del Producto (Animal Vivo, Canal, Carne y Grasa) en los Ruminates; MEC-INIA Series Ganaderas: Madrid, Spain, 2005; Volume 3. 
17. Beriain, M.J.; Sánchez, M.; Carr, T.R.A. Comparison of consumer sensory acceptance, purchase intention, and willingness to pay for high quality United States and Spanish beef under different information scenarios. J. Anim. Sci. 2014, 87, 3392-3402. [CrossRef]

18. The American Meat Science Association (AMSA). Research Guidelines for Cookery, Sensory Evaluation, and Instrumental Tenderness Measurements of Meat. In Research Guidelines for Cookery, Sensory Evaluation, and Instrumental Tenderness Measurements of Meat. American Meat Science Association, 2nd ed.; Version 1.0; The American Meat Science Association (AMSA): Champaign, IL, USA, 2015.

19. Macfie, H.J.; Bratchell, N.; Greenhoff, K.; Vallis, L.V. Designs to Balance the Effect of Order of Presentation and First-Order Carry-Over Effects in Hall Tests. J. Sens. Stud. 1989, 4, 129-148. [CrossRef]

20. Martens, H.; Naes, T. Multivariate Calibration; Wiley: Chichester, UK, 1989.

21. Jović, O.; Smolić, T.; Jurišić, Z.; Meić, Z.; Hrenara, T. Chemometric Analysis of Croatian Extra Virgin Olive Oils from Central Dalmatia Region. Croat. Chem. Acta 2013, 86, 335-344. [CrossRef]

22. Lucarini, M.; Durazzo, A.; Sánchez del Pulgar, J.; Gabrielli, P.; Lombardi-Boccia, G. Determination of Fatty Acid Content in Meat and Meat products: The FTIR-ATR approach. Food Chem. 2018, 223-230. [CrossRef]

23. Vlachos, N.; Skopelitis, Y.; Psaroudaki, M.; Konstantinidou, K.; Chatzilazarou, A.; Tegou, E. Applications of Fourier transform-infrared spectroscopy to edible oils. Anal. Chim. Acta 2006, 573, 459-465. [CrossRef]

24. Rohman, A.; Sismindari, E.Y.; Che Man, Y.B. Analysis of pork adulteration in beef meatball using Fourier transform infrared (FTIR) spectroscopy. Meat Sci. 2011, 88, 91-95. [CrossRef]

25. Oliván, M.; de La Roza, B.; Mocha, M.; Martínez, M.J. Prediction of physico-chemical and texture characteristics of beef by near infrared transmittance spectroscopy. In Proceedings of the 10th International Conference on Near Infrared Spectroscopy, Kyongju, Korea, 10-15 June 2001; pp. 197-202.

26. Lanza, E. Determination of moisture, protein, fat and calories in raw pork and beef by near infrared spectroscopy. J. Food Sci. 1983, 48, pp-471. [CrossRef]

27. Shi, H.T.; Lei, Y.G.; Prates, L.L.; Yu, P.Q. Evaluation of near-infrared (NIR) and Fourier transform mid-infrared (ATRFT/MIR) spectroscopy techniques combined with chemometrics for the determination of crude protein and intestinal protein digestibility of wheat. Food Chem. 2019, 272, 507-513. [CrossRef] [PubMed]

28. Cozzolino, D.; Murray, I.; Scaife, J.R.; Paterson, R. Study of dissected lamb muscles by visible and near infrared reflectance spectroscopy for composition assessment. Anim. Sci. 2000, 70, 417-423. [CrossRef]

29. Weeranantanaphan, J.; Downey, G.; Allen, P.; Sun, D.-W. A review of near infrared spectroscopy in muscle food analysis: 2005-2010. J. Near Infrared Spectrosc. 2011, 19, 61-104. [CrossRef]

30. Dilzer, A.; Park, Y. Implication of Conjugated Linoleic Acid (CLA) in Human Health. Crit. Rev. Food Sci. Nutr. 2012, 52, 488-513. [CrossRef] [PubMed]

31. Geesink, G.H.; Schreutelkamp, F.H.; Frankhuizen, R.; Vedder, H.W.; Faber, N.M.; Kranen, R.W.; Gerritzen, M.A. Prediction of pork quality attributes from near infrared reflectance spectra. Meat Sci. 2003, 65, 661-668. [CrossRef]

32. Andrés, S.; Murray, I.; Navajas, E.A.; Fisher, A.V.; Lambe, N.R.; Bünger, L. Prediction of sensory characteristics of lamb meat samples by near infrared reflectance spectroscopy. Meat Sci. 2007, 76, 509-516. [CrossRef]

33. Hell, J.; Prückler, M.; Danner, L.; Henniges, U.; Apprich, S.; Rosenau, T.; Kneifel, W.; Bohmdorfer, S. A comparison between near-infrared (NIR) and mid-infrared (ATR-FTIR) spectroscopy for the multivariate determination of compositional properties in wheat bran samples. Food Control 2016, 60, 365-369. [CrossRef]

34. Xing, J.; Ngadi, M.; Gunenc, A.; Prasher, S.; Gariepy, C. Use of visible spectroscopy for quality classification of intact pork meat. J. Food Eng. 2007, 82, 135-141. [CrossRef]

35. Juárez, M.; Alcalde, M.J.; Horcada, A.; Molina, A. Southern Spain lamb types discrimination by using visible spectroscopy and basic physicochemical traits. Meat Sci. 2008, 80, 1249-1253. [CrossRef]

(C) 2020 by the authors. Licensee MDPI, Basel, Switzerland. This article is an open access article distributed under the terms and conditions of the Creative Commons Attribution (CC BY) license (http://creativecommons.org/licenses/by/4.0/). 